\title{
Introduction: Climate Change and our Future
}

I am drinking and eating my way through pastures, trees, minerals, rivers, oceans, and other species. I am polluting and changing the planet's atmosphere and its oceans, and destroying the myriad species that comprise life on earth. In doing so, I am endangering my own life support systems, as I need air, water, and food to survive. Although I am capable of creating innovative ideas, and though technologies and solutions are available and known, I continue to participate in the destruction of our planetary systems, the Garden of Eden. I know the time has come to do something and declare that I shall do what it takes. This is the point of no return. May my actions help create a livable world for everyone.

195 nations negotiated a global climate pact in Paris at COP21, in December 2015. This book is about the challenges and the opportunities created by the climate crisis. It explores the irreversible dangers that we face, and the opportunities available to us now. We are at a critical point; although there exist today solutions to avert climate change, the next few years will determine whether we will implement these solutions or unleash irreversible and, possibly catastrophic, damage. We are truly at a point of no return.

In 1997, the poor and rich nations of planet Earth reached an international agreement to forestall a global 
disaster: the Kyoto Protocol of the United Nations. It became international law in 2005. For the first time, the Kyoto Protocol capped the emissions of the main emitters, the industrialized countries, one by one. It also created an innovative financial mechanism, the Carbon Market (now the EU ETS) and its Clean Development Mechanism (CDM), which allows developing nations to receive carbon credits when they reduce their emissions below their baselines. The carbon market, an economic system that created a price for carbon for the first time, is now used in four continents, is promoted by the World Bank, and is recommended by leading oil and gas companies. ${ }^{1}$ On September 24, 2015, China officially adopted the carbon market, which made global news. The CDM has the potential both to reduce the emissions responsible for climate change and to transfer wealth and clean technology to poor countries to implement the solutions that exist today. The CDM has transferred billions of dollars to poor nations for clean projects since 2005. The essence of the CDM is creating value for all, while decreasing global emissions of $\mathrm{CO}_{2}$.

The Kyoto Protocol is a historic agreement, the first of its kind. It limits global emissions and creates a new market that is based on trade in user rights to the atmosphere - the global commons - which we all share. The Kyoto Protocol is a work in progress that has taken more than 20 years to build and improve; it did succeed in getting almost all nations to cooperate to reduce global emissions and has achieved about $22.6 \%$ in the reduction of emissions since 2005 by the nations with binding commitments. ${ }^{2}$ This is a good beginning, but there is still a lot to be achieved.

First, we need to understand how we dug ourselves into this hole in order to figure out how to get out, a topic we will look at in more detail in the first chapter. The inception of industrialization two centuries ago dramatically expanded and accelerated after World War II, and depended heavily on burning fossil 
fuels - coal, oil, and natural gas - to provide energy to the economy. Energy is the mother of all markets. Everything is made with energy. Economic development still depends on the availability of cheap energy sources, and in today's global economy, this still means fossil fuels. Fossil fuels generate roughly $70 \%$ of the electricity in the world today. ${ }^{3}$

The consequences of our thirst for fossil fuels have become increasingly apparent. The science is new and there are still uncertainties, but the risks are real and solutions exist today. The Arctic Sea and glaciers are melting before our eyes. Thawing permafrost in high-latitude and highelevation regions is causing enormous damage to infrastructure and is rapidly changing ecosystems. ${ }^{4}$ According to the World Health Organization (WHO), more than 150,000 people die and millions more become ill each year because of climate change. ${ }^{5}$ Ominous signs of a changing climate abound. Heat waves in Western Europe claimed 70,000 lives in 2003, and monsoons left $24 \%$ of Bangladesh underwater in 2004. We have seen an increase in the average intensity of Atlantic hurricanes, such as Hurricanes Katrina, Sandy, and Maria, which wiped out much of the U.S.'s Louisiana and Mississippi Gulf Coast shorelines in 2005, closed down most of New York City for weeks in 2011, and destroyed much of Puerto Rico and the Caribbean in $2017 .{ }^{6}$ In the last decade, Australia suffered record droughts and widespread fires, followed by record breaking floods, and significant parts of Greenland's ice sheet and the Antarctic continent have already melted. ${ }^{7}$ The North and South Poles are rapidly melting. The Pentagon identifies climate change among its top security risks. ${ }^{8}$

\section{A Toxic Dependence}

Despite this, our demand for fossil fuels continues unabated. China is a world environmental leader, but, according to U.S. 
government projections, it will build a new 600 megawatt plant every 10 days for 10 years. ${ }^{9}$ The average U.S. consumer uses more energy today than ever before, despite advances in energy efficiency, partly because the U.S. has some of the lowest oil prices in history. Prices are heavily dependent on international market conditions and on the trade policies of some developing nations. Today's low prices follow a period when oil prices reached some of the highest levels since the Organization of the Petroleum Exporting Countries (OPEC) oil embargoes of the 1970s. The desire for energy independence has created powerful incentives for countries, including China and the U.S., to use their abundant coal and tar sands resources to meet their rapidly growing energy needs. ${ }^{10}$ This is bad news, as coal and tar sands are the worst fossil fuels in terms of the amount of carbon they emit.

Contrary to common wisdom, there are solutions today for the climate crisis, even though no silver bullets exist to rid us of our fossil fuel dependence in the short run. There are short-term solutions that involve new carbon capture technologies. These reduce the $\mathrm{CO}_{2}$ that is already in the atmosphere, as will be explained below. Long-run solutions are different, and they involve a transformation of the energy infrastructure of the world, which is worth about $\$ 55$ trillion. A former Executive Director of the International Energy Agency (IEA), Nobuo Tanaka, believes we need an energy revolution. Tanaka said in 2008 that we need to change the world's energy infrastructure at a cost of $\$ 45$ trillion by 2050, which is two-thirds of the gross domestic product (GDP) of the entire planet. ${ }^{11}$ Updated figures from 2014 show that it would take $\$ 53$ trillion by 2035 to get the world on a path to limiting warming by $2^{\circ} \mathrm{C} .{ }^{12}$ It is safe to say that this change will not happen quickly. It is a race against time.

New technologies can rid the atmosphere of its $\mathrm{CO}_{2}$, and some are starting to be used commercially. Called carbon 
negative technologies ${ }^{\mathrm{TM}}$, they can absorb the carbon that is already in the atmosphere and make this carbon into useful commercial products and services that are sold at a profit. The Intergovernmental Panel on Climate Change (IPCC) Fifth Assessment Report of 2014 and 2018 documents that removing carbon from the atmosphere is the only solution in most scenarios to avert catastrophic climate change, since we have procrastinated so much that reducing current emissions no longer averts the risk of catastrophic climate change. ${ }^{13}$ Once emitted, $\mathrm{CO}_{2}$ can stay for hundreds of years in the atmosphere. We are already well into levels that can unleash catastrophic climate change.

What is clear is that our grandchildren will inherit a world that is very different from our own. They will either inherit a planet with a severely diminished capacity to support human life or they will inherit a global economic system fueled by cleaner, renewable energy sources that respects ecological limits and is capable of meeting the basic needs of every woman, man, and child. Which path we set them on is entirely dependent on our response to this crisis. So much hinges on the choices we make now.

We have the chance to transform this crisis into an opportunity for renovating the global energy infrastructure. The clean energy industry is growing rapidly. Investment in clean energy jumped 16\% between 2013 and 2014 and current investment in this emerging industry exceeds $\$ 310$ billion. ${ }^{14}$ This is hopeful. Perhaps we can turn the crisis into a success story of human ingenuity and cooperation. But let us not get ahead of ourselves. Right now the crisis is worsening and time is running out.

One critical problem for the future is the continuing impasse between the rich and the poor nations. The U.S. has refused, so far, to ratify the Kyoto Protocol unless 
China, India, and other poor nations agree to limit emissions. On July 25, 1997, the U.S. Senate passed by a vote of 95 to 0 the Byrd-Hagel Resolution, declaring that the U.S. would not mandate commitments to limit or reduce its greenhouse gas emission unless there are commitments to limit or reduce greenhouse emissions for Developing Country Parties, and the limits do not harm the U.S. economy. Unless the two world's largest greenhouse gas emitters, U.S. and China, limit their emissions, preventing catastrophic climate change does not seem to be a possibility. How will the global community overcome this divide and forge cooperation between rich and poor countries? ${ }^{15}$

In a nutshell, the question comes down to this: who should reduce emissions - the rich or the poor countries?

The rich nations depended heavily on fossil fuels to grow while the rest of the world were left behind. Today, developing and developed countries contribute approximately equal shares of cumulative greenhouse gas emissions for the period of 1850-2010, while developing nations house $83.3 \%$ of the world population. ${ }^{16}$ Now, poor countries say that it is their turn to industrialize. Can we really ask poor countries to sacrifice their development opportunities now to atone for the rich nations' past sins? Can we suddenly change the rules of industrial development by requiring countries to find a non-fossil fuel dependent path to development? We can try, but we may very well fail. Rich countries, and in particular the U.S., have little credibility at this stage, and many developing nations, such as India, China, and Brazil, are beginning to flex their economic muscles. Accompanying this is a rapid increase in energy use and carbon emissions.

There is a more basic issue at stake. The developing nations do not emit enough today to resolve the problem by 


\section{$\mathrm{CO}_{2}$ Emissions (2012)}

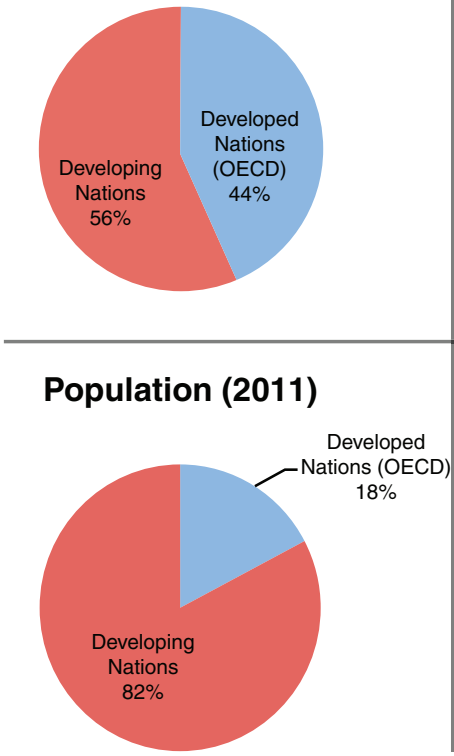

Cumulative $\mathrm{CO}_{2}$ Emissions

(1990-2012)

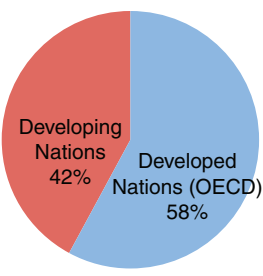

GDP (2012)

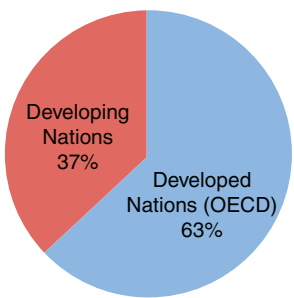

Figure 1 Distribution of world wealth, population, and emissions Source: OECD: https://stats.oecd.org; The World Bank: http://data.worldbank.org.

themselves unless they stop producing emissions altogether and start using carbon negative technologies. Together, the poor nations emit approximately half of the world's emissions (see Figure 1 "Distribution of World Wealth, Population and Emissions"). Africa, for example, emits only $3 \%$ of the global emissions; South America approximately 5.5\%. ${ }^{17}$ Even if every woman, man, and child in the developing nations, all 5 billion people, stopped emitting any carbon today to oblige the rest - which would require that their citizens stop breathing - they would still not resolve the problem. Developed nations need to reduce global emissions by at least $40 \%$, possibly $70 \%$ by $2050 .{ }^{18}$ Given who the big emitters are now, the obvious way to achieve this is to decrease emissions in both the industrialized and developing world, working in unison to solve our collective problem. 
More importantly, we need to clean up the $\mathrm{CO}_{2}$ built up in the atmosphere over the last hundred years.

Should the countries that are most responsible for creating the global climate crisis take the lead in solving it? Should the countries that are best able to afford emissions reductions shoulder more of the burden? In 1997, the Kyoto Protocol answered yes to both of these questions and excused developing countries from mandatory emission cuts at that point in time. But times have changed. Developing nations such as China now emit more than the U.S., and the responsibility for global climate change has changed since the Kyoto Protocol was introduced in 1997. ${ }^{19}$ It is true that China has four times more people than the U.S. Indeed, China has about 1.4 billion people while the U.S. has about 330 million. ${ }^{20}$ Therefore, the average Chinese person is still much more frugal in energy use than the average American.

At the same time, we need to be aware that 20 years from now developing nations could create catastrophic global warming for the entire planet by doing exactly what the rich nations did during their industrialization period: using their own resources to burn fossil fuels. For example, South Africa is the world's fifth largest producer and the sixth largest consumer of coal. ${ }^{21}$ This is why the solution to the climate crisis involves all of us. It is truly a one-world problem that nobody can escape.

This book explains why international cooperation between rich and poor nations is crucial in order to prevent catastrophic climate change. The stage for international cooperation has already been set.

The Kyoto Protocol, the only mandatory international treaty to combat climate change, created a carbon market that can unite environmental and economic interests. Its unique 
properties ensure that our efforts to combat climate change are both fair and efficient. The carbon market - a young market for a global public good - is distinct from any other market in history. That is exactly why it is still a work in progress, even though it has been adopted successfully in four continents. It needs all the help it can get to evolve into a successful solution. Climate change is a complex phenomenon, and it must be recognized that, in the long-run, massive reforestation, hydrological restoration, and a more fundamental respect for life, as a whole, may be needed, topics that go beyond the scope of this book.

This book outlines the history of global climate negotiations that led to the Kyoto Protocol and the Paris Agreement, from the perspective of Graciela Chichilnisky, the architect of the Protocol's carbon market. The Kyoto Protocol carbon emissions limits expire in December 2020, and the 2015 meeting in Paris COP21 did not consider their extension. Many difficult political and economic challenges lie ahead. Although frustration has dominated most of the annual Convention of the Parties, they are still our generation's only uniting force in the struggle against climate change. On June 1, 2017, President Trump decided that the U.S. would withdraw from the 2015 Paris Agreement and, on November 4, 2019, Secretary of State Michael Pompeo began the process to officially withdraw. The withdrawal will take effect one year from delivery of the notification. 